\title{
Higher Concentrations of Heparin and Hirudin Are Required to Inhibit Thrombin Generation in Tissue Factor-Activated Cord Plasma Than in Adult Plasma
}

\author{
KATRIN BAIER, GERHARD CVIRN, PETER FRITSCH, MARTIN KÖSTENBERGER, \\ SIEGFRIED GALLISTL, BETTINA LESCHNIK, AND WOLFGANG MUNTEAN \\ Ludwig Boltzmann Research Institute for Pediatric Hemostasis and Thrombosis [K.B., G.C., P.F., W.M.], \\ Department of Pediatrics [K.B., P.F., M.K., S.G., B.L., W.M.], and Institute of Medical Chemistry and \\ Pregl Laboratory [G.C.], Medical University of Graz, Graz, Austria
}

\begin{tabular}{|c|c|}
\hline \multicolumn{2}{|c|}{ ABSTRACT } \\
\hline $\begin{array}{l}\text { Neonatal plasma clots slower than adult plasma, and only } \\
30-50 \% \text { of peak adult thrombin activity can be produced in } \\
\text { neonatal plasma when high amounts of tissue factor (TF) are } \\
\text { added to trigger clotting, as used in standard clotting assays. } \\
\text { Plasma activation by addition of low amounts of TF probably } \\
\text { better reflects conditions in vivo. Under these conditions, cord } \\
\text { plasma clots faster than adult plasma. In the present study, we } \\
\text { show that after activation with low amounts of TF, higher } \\
\text { amounts of the anticoagulants heparin and hirudin are required in } \\
\text { cord plasma for effective inhibition of thrombin generation com- } \\
\text { pared with adult plasma. After strong activation with high } \\
\text { amounts of TF ( } 30 \mu \mathrm{M}) \text {, the thrombin potential was significantly } \\
\text { more suppressed in cord plasma compared with adult plasma in } \\
\text { the presence of } 0.4 \mathrm{IE} / \mathrm{mL} \text { heparin }(-92 \text { versus }-75 \% ; p<0.01) \\
\text { and in the presence of } 2 \mathrm{IE} / \mathrm{mL} \text { hirudin ( }-18 \text { versus }-8 \% ; p< \\
0.01 \text { ). In contrast, after weak activation with low amounts of TF }\end{array}$ & $\begin{array}{l}(30 \mathrm{pM}) \text {, the thrombin potential was significantly more sup- } \\
\text { pressed in adult plasma compared with neonatal plasma in the } \\
\text { presence of } 0.025 \mathrm{IE} / \mathrm{mL} \text { heparin }(-93 \text { versus }-8 \% ; p<0.01) \\
\text { and in the presence of } 2 \mathrm{IE} / \mathrm{mL} \text { hirudin }(-89 \text { versus }-48 \% ; p< \\
0.01) \text {. Our results show that in neonates, effects of anticoagulants } \\
\text { very much depend on the type of activation used to initiate } \\
\text { clotting, and doses of anticoagulants should not be derived from } \\
\text { studies done in adults, because potentially higher doses of anti- } \\
\text { coagulants may be required. (Pediatr Res 57: 685-689, 2005) }\end{array}$ \\
\hline
\end{tabular}

The hemostatic system of neonates is different from that of children and adults. Neonates have lower levels of most procoagulant factors, especially prothrombin, other factors of the prothrombin complex (VII, IX, and X), and contact factors. This is reflected in prolonged prothrombin time and activated partial thromboplastin time. Physiologic low levels of anticoagulant proteins in neonatal plasma might compensate for low levels of coagulation factors and allow sufficient thrombin generation. In neonatal plasma, antithrombin (AT) is reduced to $\sim 50 \%$ of adult values (1). These physiologic low AT levels result in an impaired ability of neonatal plasma to inhibit thrombin compared with adult plasma (2).

Received March 8, 2004; accepted September 10, 2004.

Correspondence: Wolfgang Muntean, M.D., Ludwig Boltzmann Research Institute for Pediatric Hemostasis and Thrombosis, Medical University of Graz, Auenbruggerplatz 30 A-8036, Graz, Austria; e-mail: wolfgang.muntean@meduni-graz.at.

This study was supported by a grant from the "Gesellschaft zur Förderung der Gesundheit unserer Kinder (INVITA)" and the "Franz-Lanyar-Stiftung."

DOI: 10.1203/01.PDR.0000156515.49293.F8
It has been suggested that decreased concentrations of heparinoids are required to inhibit thrombin generation in cord plasma to the same extent as in adults as a result of reduced neonatal thrombin potential (TP) (3). The thrombin generation curve, i.e. the course of appearance and disappearance of thrombin in triggered plasma, gives information on the process of blood coagulation that is difficult to obtain otherwise. The TP is the area under the thrombin generation curve and has been shown to be a valid parameter for detection of possible hypo- or hypercoagulable states (4-6). However, thrombin generation is delayed only in cord plasma compared with adults after addition of high amounts of activator, as is usually done in the conventional clotting assays activated partial thromboplastin time or prothrombin time. Strong activators were also used in the neonatal studies mentioned above. Under these conditions, only $30-50 \%$ of peak adult thrombin activity can be produced in cord plasma (7).

Plasma activation as a result of addition of low amounts of tissue factor (TF) probably better reflects the conditions in vivo and allows sensitive detection of the effects of pro- and anticoagulants on thrombin generation $(8,9)$. In previous work, we 
showed that under activation with low amounts of activator, in contrast to the findings in the presence of high amounts of activator, thrombin generation in cord plasma starts earlier than in adult plasma (10-15). This good thrombin-forming capacity of cord compared with adult plasma is caused by the low anticoagulant action of the natural inhibitors TF pathway inhibitor (TFPI), AT, and activated protein $\mathrm{C}$ in newborns $(10,16,17)$. Thus, one might assume that higher concentrations of anticoagulants might be required in neonates to inhibit thrombin generation to the same extent as in adults in the presence of low amounts of initiator of clot formation.

Therefore, it was the aim of our study to evaluate the anticoagulant action of the anticoagulants heparin and hirudin under activation with low amounts of the initiator TF (probably better reflecting the conditions in vivo) in comparison with that with high amounts of initiator (reflecting the conditions that prevail in standard clotting assays). We investigated the effects of increasing amounts of both an indirect and a direct inhibitor of thrombin, heparin and hirudin, on prolongation of clotting time and on suppression of TP in both cord and adult plasma in the presence of high (30 $\mu \mathrm{M}$ final concentration) or low (30 pM final concentration) amounts of TF in an effort to better understand the mechanisms of anticoagulation with indirect and direct thrombin inhibitors in neonates and provide a rationale for dose finding in neonates.

\section{METHODS}

Reagents. Buffer A contained $0.05 \mathrm{M}$ Tris- $\mathrm{HCl}$ at $\mathrm{pH} 7.4,0.1 \mathrm{M} \mathrm{NaCl}$, and $0.5 \mathrm{M}$ BSA. Buffer B was analogous to buffer A but contained in addition 20 mM EDTA.

Full-length lipidated recombinant human TF (a stock solution was prepared by dissolving $50 \mathrm{ng}$ of the lyophilized lipoprotein in $4.5 \mathrm{~mL}$ of buffer $\mathrm{A}$; aliquots of $500 \mu \mathrm{L}$ were stored at $-70^{\circ} \mathrm{C}$ ), and Actichrome TF activity assay was obtained from American Diagnostica (Greenwich, CT). Heparin (1000 $\mathrm{IE} / \mathrm{mL}$ ) was obtained from Baxter Hyland Immuno (Vienna, Austria). A stock solution of $10 \mathrm{IE} / \mathrm{mL}$ was prepared by 1:100 dilution with distilled water. Hirudin was obtained from Sigma Chemical Co. (Vienna, Austria). A total of $500 \mathrm{IE}$ was dissolved in $1 \mathrm{~mL}$ of distilled water and subsequent 1:10 dilution in buffer A. For strong activation of plasma samples, we used Thromborel S as a source of TF, obtained from Behring Diagnostics (Marburg, Germany), which contained human placental thromboplastin and calcium chloride. The fibrin polymerization inhibitor H-Gly-Pro-Arg-Pro-OH (Pefabloc FG) was purchased from Pentapharm LDT (Basel, Switzerland). The chromogenic substrate used for thrombin determination was H-D-Phe-Pip-Arg-pNA.2HCl (pNAPEP 0238) from CoaChrom Diagnostics (Vienna, Austria). Twenty-five milligrams of the lyophilized substrate were dissolved in $7 \mathrm{~mL}$ of distilled water to a concentration of $5.7 \mathrm{mM}$.

Collection and preparation of plasma. Cord blood was obtained immediately after the delivery of 16 full-term infants (38-42 wk gestational age). Newborns with Apgar scores of 9 or less 5 min after delivery were excluded from the study. Blood $(2.7 \mathrm{~mL})$ was collected into precitrated S-Monovette premarked tubes from Sarstedt (Nümbrecht, Germany), which contained 300 $\mu \mathrm{L}$ of $0.106 \mathrm{M}$ citrate, centrifuged at room temperature for $10 \mathrm{~min}$ at $4100 \times$ $g$, pooled, and stored at $-70^{\circ} \mathrm{C}$ in propylene tubes until assayed. The hematocrit of cord blood was similar to that of adult blood. FV and FVIII activities were elevated over the respective adult values; other pro- and anticoagulant factors were in the normal range for neonates, i.e. cord plasma contained $49 \pm$ $4.2 \mu \mathrm{g} / \mathrm{mL}$ prothrombin, $22 \pm 1.8 \mathrm{ng} / \mathrm{mL}$ TFPI, and $172 \pm 14.9 \mu \mathrm{g} / \mathrm{mL}$ AT. In the same way, plasma from 14 healthy adults was collected from the antecubital vein, prepared, checked, and stored at $-70^{\circ} \mathrm{C}$ in propylene tubes until assayed. Adult plasma contained $103 \pm 9.1 \mu \mathrm{g} / \mathrm{mL}$ prothrombin, $58 \pm$ $4.9 \mathrm{ng} / \mathrm{mL}$ TFPI, and $294 \pm 23.2 \mu \mathrm{g} / \mathrm{mL}$ AT.

Determination of TF concentration. TF procoagulant activity was quantified by means of the Actichrome TF activity assay, with an intra-assay coefficient of variance of $7.3 \%$ and an interassay coefficient of variance of $6.9 \%$.
Activation of plasma. A total of $380 \mu \mathrm{l}$ of plasma was incubated with 20 $\mu \mathrm{L}$ of buffer A that contained different amounts of heparin $(0-0.5 \mathrm{IE} / \mathrm{mL})$ or hirudin $(0-2.5 \mathrm{IE} / \mathrm{mL})$ for $1 \mathrm{~min}$ at $37^{\circ} \mathrm{C}$. Subsequently, $20 \mu \mathrm{L}$ of buffer A that contained H-Gly-Pro-Arg-Pro-OH (Pefabloc FG, $1.0 \mathrm{mg} / \mathrm{mL}$ final concentration) to inhibit fibrin polymerization (4) was added. Subsequently, $40 \mu \mathrm{L}$ of buffer A that contained TF (30 pM final concentration) or Thromborel S (30 $\mu \mathrm{M}$ final concentration of TF) for $1 \mathrm{~min}$ at $37^{\circ} \mathrm{C}$ was added. Finally, $10 \mu \mathrm{L}$ of $0.5 \mathrm{M} \mathrm{CaCl}_{2}$ was added to trigger clot formation at $37^{\circ} \mathrm{C}$.

Determination of clotting time. Plasma was activated as described above except that Pefabloc FG was replaced by buffer A. Clotting times were determined by means of the optomechanical coagulation analyzer Behring Fibrintimer II from Behring Diagnostics, which applies the turbodensitometric measuring principle.

Determination of thrombin generation. We used a subsampling method derived from a recently described technique $(4-5,14)$. Plasmas were prepared and activated as described above. At timed intervals, $10-\mu \mathrm{L}$ aliquots were withdrawn from the activated plasma and subsampled into $490 \mu \mathrm{L}$ of buffer B that contained $255 \mu \mathrm{M}$ pNAPEP 0238. Amidolysis of pNAPEP 0238 was stopped after 6 min by addition of $250 \mu \mathrm{L}$ of $50 \%$ acetic acid. The amount of thrombin generated was quantified by measuring the absorbance by double wave length (405-690 nm) in the Anthos microplate reader 2001, from Anthos Labtec Instruments (Salzburg, Austria). The total amidolytic activity measured is caused by the simultaneous activity of free thrombin and the $\alpha 2$ macroglobulin-thrombin complex. Free thrombin generation curves were calculated by mathematical treatment of total amidolytic activity curves using a method developed by Hemker et al. (5).

Statistical analysis. Results obtained in cord and adult plasma were compared by means of Mann Whitney $U$ test. The effects of different concentrations of heparin or hirudin on clotting time, and TP were analyzed using Wilcoxon test. The significance level of $p$ values was set at 5\%. Calculations were performed using Winstat 3.1 (Kalmia Co., Cambridge, MA). The study was approved by the applicable Institutional Review Board, and informed consent was obtained.

\section{RESULTS}

Clotting times of cord and adult plasma in the absence of inhibitors. Clotting times of cord and adult plasma were 49 and $30 \mathrm{~s}$, respectively, in the presence of $30 \mu \mathrm{M}$ of $\mathrm{TF}$ to induce clot formation and 316 and $455 \mathrm{~s}$, respectively, in the presence of $30 \mathrm{pM}$ of TF to induce clot formation.

Effect of increasing amounts of heparin on clotting time. After activation with high and low amounts of TF (30 $\mu \mathrm{M}$ and 30 $\mathrm{pM}$ of TF were applied to trigger clot formation, respectively), clotting time was dose-dependently prolonged in both cord and adult plasma in the presence of increasing amounts of heparin (Fig. 1), whereby prolongation of clotting time was significantly more pronounced in adult plasma after activation with low amounts of TF compared with that in cord plasma ( $p<0.01$; Fig. 1A). No clot formation within $15 \mathrm{~min}$ was observed in adult plasma after activation with low amounts of $\mathrm{TF}$ at heparin concentrations that exceeded $0.025 \mathrm{IE} / \mathrm{mL}$ and in cord plasma at heparin concentrations that exceeded $0.175 \mathrm{IE} / \mathrm{mL}$ (Fig. 1A). On the contrary, prolongation of clotting time was significantly more pronounced in cord plasma after activation with high amounts of
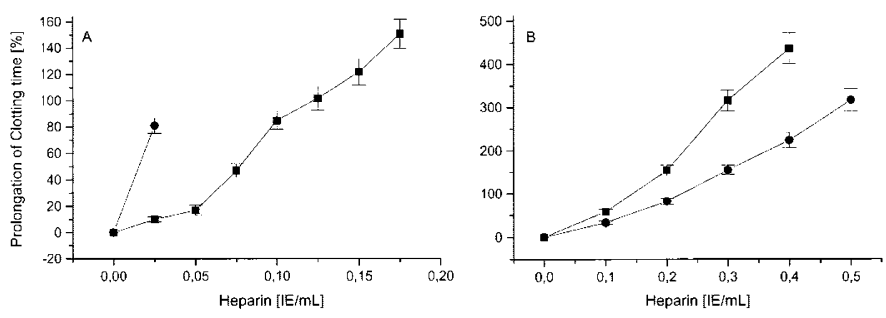

Figure 1. Effect of addition of heparin on prolongation of clotting time in cord $(\square)$ and adult $(\bullet)$ plasma in the presence of $30 \mathrm{pM}(A)$ and $30 \mu \mathrm{M}(B)$ of TF to induce clot formation. Results are expressed as means $(n=5)$. 
TF compared with that in adult plasma $(p<0.01$; Fig. $1 B)$. No clot formation within $15 \mathrm{~min}$ was observed in adult plasma after activation with high amounts of TF at heparin concentrations that exceeded $0.5 \mathrm{IE} / \mathrm{mL}$ and in cord plasma at heparin concentrations that exceeded $0.4 \mathrm{IE} / \mathrm{mL}$ (Fig. $1 B$ ).

Effect of increasing amounts of heparin on TP. After activation with high and low amounts of TF, suppression of thrombin generation dose-dependently increased in the presence of increasing amounts of heparin in both cord and adult plasma (Fig. 2), whereby the anticoagulant action of heparin was significantly more pronounced in adult plasma after activation with low amounts of TF compared with that in cord plasma ( $p<0.01$; Fig. $2 A$ ). Virtually no thrombin formation within 15 min was detected in adult plasma after activation with low amounts of $\mathrm{TF}$ at heparin concentrations that exceeded $0.025 \mathrm{IE} / \mathrm{mL}$ and in cord plasma at heparin concentrations that exceeded $0.175 \mathrm{IE} / \mathrm{mL}$ (Fig. $2 A$ ). On the contrary, suppression of thrombin generation as a result of addition of heparin was significantly more pronounced in cord plasma after activation with high amounts of TF compared with that in adult plasma $(p<0.01$; Fig. $2 B)$. Virtually no thrombin formation within 15 min was observed in adult plasma after activation with high amounts of TF at heparin concentrations that exceeded $0.5 \mathrm{IE} / \mathrm{mL}$ and in cord plasma at heparin concentrations that exceeded $0.4 \mathrm{IE} / \mathrm{mL}$ (Fig. $2 B$ ).

Effect of increasing amounts of hirudin on clotting time. After activation with high and low amounts of TF, the clotting time was dose-dependently prolonged in both cord and adult plasma in the presence of increasing amounts of hirudin (Fig. 3 ), whereby prolongation of clotting time was significantly more pronounced in adult plasma after activation with low amounts of TF compared with that in cord plasma $(p<0.01$; Fig. 3A). No clot formation within 15 min was observed in adult plasma after activation with low amounts of TF at hirudin concentrations that exceeded $2.0 \mathrm{IE} / \mathrm{mL}$ and in cord plasma at hirudin concentrations that exceeded $2.5 \mathrm{IE} / \mathrm{mL}$ (Fig. 3A). Prolongation of clotting time was significantly more pronounced in cord plasma after activation with high amounts of TF compared with that in adult plasma $(p<0.01$; Fig. $3 B)$. Both cord and adult plasma still clotted within 15 min after activation with high amounts of TF even when hirudin concentrations up to $2.5 \mathrm{IE} / \mathrm{mL}$ were added.

Effect of increasing amounts of hirudin on TP. After activation with high and low amounts of TF, suppression of thrombin generation dose-dependently increased in the presence of increasing amounts of hirudin in both cord and adult
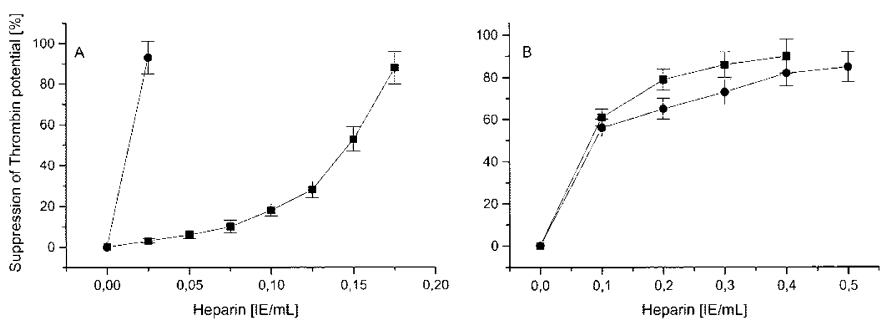

Figure 2. Effect of addition of heparin on suppression of TP in cord ( $\square$ ) and adult (O) plasma in the presence of $30 \mathrm{pM}(A)$ and $30 \mu \mathrm{M}(B)$ of TF to induce clot formation. Results are expressed as means $(n=5)$.
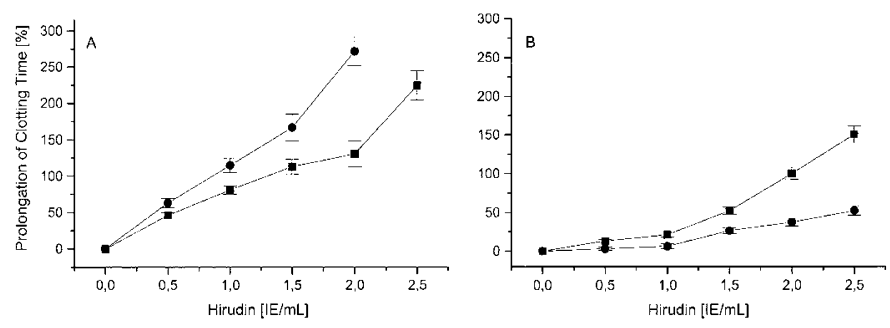

Figure 3. Effect of addition of hirudin on prolongation of clotting time in cord $\square)$ and adult (O) plasma in the presence of $30 \mathrm{pM}(A)$ and $30 \mu \mathrm{M}(B)$ of TF to induce clot formation. Results are expressed as means $(n=5)$.

plasma (Fig. 4), whereby the anticoagulant action of hirudin was significantly more pronounced in adult plasma after activation with low amounts of TF compared with that in cord plasma ( $p<0.01$; Fig. $4 A$ ). Virtually no thrombin formation within 15 min was observed in adult plasma after activation with low amounts of $\mathrm{TF}$ at hirudin concentrations that exceeded $2.0 \mathrm{IE} / \mathrm{mL}$ and in cord plasma at hirudin concentrations that exceeded $2.5 \mathrm{IE} / \mathrm{mL}$ (Fig. $4 A$ ). On the contrary, suppression of thrombin generation as a result of addition of hirudin was significantly more pronounced in cord plasma after activation with high amounts of TF compared with that in adult plasma $(p<0.01$; Fig. $4 B$ ). For significant suppression of thrombin generation in adult plasma, hirudin concentrations that exceeded $2.5 \mathrm{IE} / \mathrm{mL}$ were required (Fig. $4 B$ ).

Comparison of the anticoagulant action of heparin (suppression of thrombin generation) in cord and adult plasma in the presence of low amounts of $T F$ with that in the presence of high amounts of TF as initiator of clot formation. Suppression of thrombin generation as a result of addition of 0.025 $\mathrm{IE} / \mathrm{mL}$ heparin was significantly more pronounced in adult than in cord plasma $(-93$ versus $-8 \% ; p<0.01)$ in the presence of low amounts of TF (Fig. 5A). On the contrary, suppression of thrombin generation as a result of addition of $0.4 \mathrm{IE} / \mathrm{mL}$ heparin was significantly more pronounced in cord than in adult plasma ( -92 versus $-75 \% ; p<0.01)$ in the presence of high amounts of TF (Fig. 5B). Same results were obtained in all high coagulant challege-experiments whether Thromborel was used as a source of TF or high amounts of lipidated recombinant human tissue factor were applied to trigger blot formation.

Comparison of the anticoagulant action of hirudin (suppression of thrombin generation) in cord and adult plasma in the presence of low amounts of $T F$ with that in the presence of high amounts of TF as initiator of clot formation. Suppression of thrombin generation as a result of addition of 2
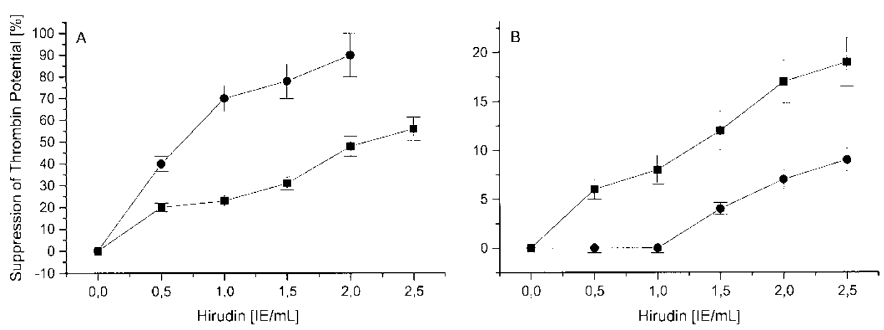

Figure 4. Effect of addition of hirudin on thrombin generation in cord ( and adult (O) plasma in the presence of $30 \mathrm{pM}(A)$ and $30 \mu \mathrm{M}(B)$ of TF to induce clot formation. Results are expressed as means $(n=5)$. 

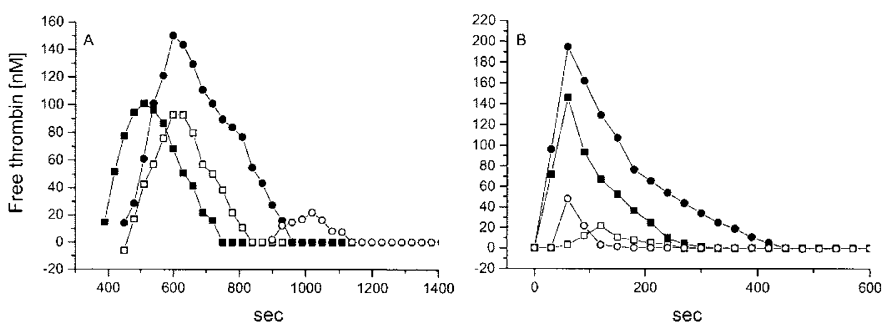

Figure 5. Thrombin generation in cord plasma ( $\square$ ), in cord plasma that contained $0.025 \mathrm{IE} / \mathrm{mL}$ heparin $(A)$ or $0.4 \mathrm{IE} / \mathrm{mL}$ heparin $(B ; \square)$, in adult plasma (๑), and in adult plasma that contained $0.025 \mathrm{IE} / \mathrm{mL}$ heparin $(A)$ or 0.4 $\mathrm{IE} / \mathrm{mL}(B ; \bigcirc)$, in the presence of $30 \mathrm{pM}(A)$ or $30 \mu \mathrm{M}(B)$ of $\mathrm{TF}$ to induce clot formation.

$\mathrm{IE} / \mathrm{mL}$ hirudin was significantly more pronounced in adult than in cord plasma $(-89$ versus $-48 \% ; p<0.01)$ in the presence of low amounts of TF (Fig. 6A). On the contrary, suppression of thrombin generation as a result of addition of $2 \mathrm{IE} / \mathrm{mL}$ hirudin was significantly more pronounced in cord than in adult plasma $(-18$ versus $-8 \% ; p<0.01)$ in the presence of high amounts of TF (Fig. 6B).

\section{DISCUSSION}

The excellent hemostasis in neonates despite physiologic low levels of procoagulant proteins is not completely understood so far (18). Healthy neonates show no easy bruising and good wound healing. Developmental hemostasis, which refers to agedependent changes in the coagulation system, is likely also an important reason for age-related differences in the epidemiology of thromboembolic diseases. The risk for thromboembolic complications is considerably less for newborns and children than for adults for any given insult. Within the group of infants and children, newborns and infants $<1 \mathrm{y}$ of age are at the greatest risk for thromboembolic complications $(19,20)$. Despite these agerelated differences, antithrombotic therapy in children is based on adult therapeutic guidelines. The different results obtained in this study with different amounts of activators in cord and adult plasma suggest that results from investigations in adults cannot be the basis for dose finding in neonates.

The high amounts of activators applied in standard clotting assays probably do not reflect the conditions that prevail in the clinical situation (21). In conventional clotting assays, high amounts of initiator (TF in the micromolar range) are applied to trigger clot formation. Under these conditions, adult plasma
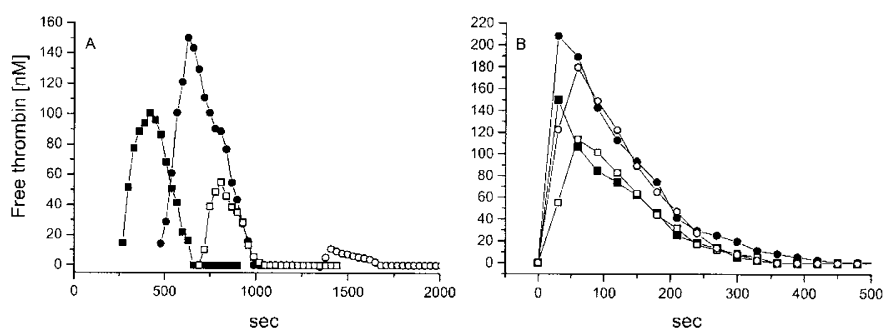

Figure 6. Thrombin generation in cord plasma ( $\square$ ), in cord plasma that contained $2 \mathrm{IE} / \mathrm{mL}$ hirudin $(\square)$, in adult plasma $(\mathbf{)})$, and in adult plasma that contained $2 \mathrm{IE} / \mathrm{mL}$ hirudin $(\bigcirc)$, in the presence of $30 \mathrm{pM}(A)$ or $30 \mu \mathrm{M}(B)$ of $\mathrm{TF}$ to induce clot formation. clots faster than cord plasma, and the capability of neonatal plasma to generate thrombin is delayed and reduced as compared with that in adult plasma (Figs. 2 and $4 B$ ), as a result of decreased prothrombin and increased $\alpha_{2}$-macroglobulin (1$2,22)$. It was reported that under these conditions, lower amounts of anticoagulants are required in cord plasma to suppress thrombin generation to the same extent as in adult plasma (3).

The effects of inhibitors can better be shown in the presence of low amounts of activator. Thus, activation of plasma samples by means of low amounts of initiator (TF in the picomolar range) has been applied in the majority of laboratory investigations in the last years $(8,9,21)$. Our findings in previous studies that with low amounts of activators, in contrast to the results with high amounts of activators, cord plasma clots faster compared with adult plasma help to explain the clinical findings that neonates have an excellent hemostasis despite clotting factor levels that would render adults prone to easy bruising. Our results confirmed the assumption that the combined physiologic low anticoagulant action of the three inhibitors TFPI, AT, and protein C in cord plasma allows shorter clotting times compared with adult plasma when low amounts of TF are applied to initiate clot formation (22). In the present study, we show that after activation with low amounts of $\mathrm{TF}$, significantly higher amounts of the anticoagulants heparin and hirudin are required to inhibit thrombin generation in cord plasma to the same extent as in adult plasma, completely contradicting the dosage requirements derived from experiments performed in the presence of high amounts of initiator (Figs. 2 and 4).

AT is potentiated by heparinoids. When AT is decreased, even with strong activation, a diminished effect of heparin can be shown, as demonstrated in adults with various diseases. Therefore, it would be expected in cord plasma that as a result of low AT, heparin has only a little effect. Thus, the reported findings that decreased concentrations of heparinoids are required to inhibit thrombin generation in neonates compared with adults (3) were unexpected. In our experiments, we also observed that after activation with high amounts of TF, heparin has a strong effect in cord plasma. These findings suggest that under these conditions, the low prothrombin level has a strong influence on TP; thus, the ratio of AT/prothrombin likely determines the in vitro sensitivity or resistance of cord plasma to heparin (23). In contrast, compared with the results under strong activation, under weak activation, the TP of neonates barely decreased after therapeutic amounts of heparin were added to cord plasma, but the effect on adult TP was very strong at the same heparin concentration (Fig. 2).

The direct thrombin inhibitor hirudin binds directly to thrombin and functions independent of antithrombin (24). In this investigation, the original idea to investigate a direct inhibitor was that AT is low in neonates and a direct inhibitor such as hirudin might be advantageous in neonates. Our results confirm this assumption that a direct inhibitor has stronger effects in cord plasma. Much higher amounts of heparin than hirudin compared with adult plasma were required in cord plasma for complete suppression of thrombin generation (Fig. 2 and $4 A)$. 


\section{CONCLUSION}

In conclusion, results from our in vitro study show that decreased amounts of anticoagulants are required in cord plasma to inhibit thrombin generation to the same extent as in adults after strong activation, but increased amounts of anticoagulants are required to suppress thrombin generation to the same extent as in adults after weak activation. Our results suggest that in neonates, effects of anticoagulants very much depend on the type of activation used to initiate clotting, and doses of anticoagulants cannot be derived from studies done in adults. If we assume that weak activation better reflects the in vivo situation, then our study suggests that higher doses of thrombin inhibitors, both indirect and direct, may be required in neonates to exhibit adequate anticoagulation effects.

Acknowledgments. We thank Yvonne Gallistl for secretarial assistance.

\section{REFERENCES}

1. Andrew M, Paes B, Milner R, Johnston M, Mitchell L, Tollefsen DM, Powers P 1987 Development of the human coagulation system in the full-term infant. Blood 70:165 172

2. Mitchell L, Piovella F, Ofosu F, Andrew M 1991 Alpha-2-macroglobulin may provide protection from thromboembolic events in antithrombin III-deficient children. Blood 78:2299-2304

3. Chan AK, Berry LR, Monagle PT, Andrew M 2002 Decreased concentrations of heparinoids are required to inhibit thrombin generation in plasma from newborns and children compared to plasma from adults due to reduced thrombin potential. Thromb Haemost 87:606-613

4. Hemker HC, Wielders S, Kessels H, Beguin S 1993 Continuous registration of thrombin generation in plasma, its use for the determination of the thrombin potential. Thromb Haemost 70:617-624

5. Hemker HC, Willems GM, Beguin S 1986 A computer assisted method to obtain the prothrombin activation velocity in whole plasma independent of thrombin decay processes. Thromb Haemost 56:9-17

6. Wielders S, Mukherjee M, Michiels J, Rijkers DT, Cambus JP, Knebel RW, Kakka V, Hemker HC, Beguin S 1997 The routine determination of the endogenous thrombin potential, first results in different forms of hyper- and hypocoagulability. Thromb Haemost 77:629-636
7. Andrew M, Schmidt B, Mitchell L, Paes B, Ofosu F 1990 Thrombin generation in newborn plasma is critically dependent on the concentration of prothrombin. Thromb Haemost 63:27-30

8. Davie EW, Fujikawa K, Kisiel W 1991 The coagulation cascade: initiation, maintenance, and regulation. Biochemistry 30:10363-10370

9. Butenas S, van't Veer C, Mann KG 1999 "Normal" thrombin generation. Blood 94:2169-2178

10. Cvirn G, Gallistl S, Rehak T, Jürgens G, Muntean W 2003 Elevated thrombinforming capacity of tissue factor-activated cord compared with adult plasma. J Thromb Haemost 1:1785-1790

11. Cvirn G, Gallistl S, Leschnik B, Muntean W 2003 Low tissue factor pathway inhibitor (TFPI) together with low antithrombin allows sufficient thrombin generation in neonates. J Thromb Haemost 1:263-268

12. Cvirn G, Gallistl S, Koestenberger M, Kutschera J, Leschnik B, Muntean W 2002 Alpha 2-macroglobulin enhances prothrombin activation and thrombin potential by inhibiting the anticoagulant protein $\mathrm{C} /$ protein $\mathrm{S}$ system in cord and adult plasma. Thromb Res 105:433-439

13. Cvirn G, Gallistl S, Muntean W 2001 Alpha-2-macroglobulin inhibits the anticoagulant action of activated protein $\mathrm{C}$ in cord and adult plasma. Haemostasis 31:1-11

14. Cvirn G, Gallistl S, Muntean W 2001 Effects of alpha (2)-macroglobulin and antithrombin on thrombin generation and inhibition in cord and adult plasma. Thromb Res 101:183-191

15. Cvirn G, Gallistl S, Muntean W 1999 Effects of antithrombin and protein C on thrombin generation in newborn and adult plasma. Thromb Res 93:183-190

16. van't Veer C, Golden NJ, Kalafatis M, Mann KG 1997 Inhibitory mechanism of the protein $\mathrm{C}$ pathway on tissue factor-activated thrombin generation. Synergistic effect in combination with tissue factor pathway inhibitor. J Biol Chem 272:7983-7994

17. van't Veer C, Mann KG 1997 Regulation of tissue factor initiated thrombin generation by the stoichiometric inhibitors tissue factor pathway inhibitor, antithrombin-III, and heparin cofactor-II. J Biol Chem 272:4367-4377

18. David M, Andrew M 1994 Venous thromboembolic complications in children J Pediatr 124:831-832

19. Andrew M, David M, Adams M, Ali M, Anderson R, Barnard D, Bernstein M, Brisson L, Cairney B, DeSai D, Grant R, Israels S, Jardine L, Luke B, Massicote P, Silvia M 1994 Venous thromboembolic complications (VTE) in children: first analyses of the Canadian registry of VTE. Blood 83:1251-1257

20. David M, Andrew M Venous thromboembolic complications in children J Pediat 123:337-346, 1993

21. Mann KG, Brummel K, Butenas S 2003 What is all that thrombin for? J Thromb Haemost 1:1504-1514

22. Schmidt B, Mitchell L, Ofosu F, Andrew M 1989 Alpha-2-macroglobulin is an important progressive inhibitor of thrombin in neonatal and infant plasma. Thromb Haemost 62:1074-1077

23. Viera A, Berry L, Ofosu F, Andrew M 1991 Heparin sensitivity and resistance in the neonate: an explanation. Thromb Res 63:85-98

24. Linder R, Blomback M, Egberg N, Grip L 1999 Thrombin inhibitors suppress the thrombin-thrombomodulin-mediated generation of activated protein $\mathrm{C}$. Thromb Res 95:117-125 